\title{
Pensar teologicamente a pandemia à luz de alguns escritos do Papa Francisco
}

\section{Thinking theologically about the pandemic in the light of some writings by Pope Francis}

\author{
José Aguiar Nobre \\ Elizeu da Conceição
}

\section{Resumo}

A partir de alguns escritos do Papa Francisco, percebemos que é possível pensar teologicamente a pandemia. Nota-se que, paradoxalmente, as incertezas causadas pela tragédia pandêmica do coronavírus pode colocar o ser humano na direção de um novo jeito de viver. Inevitavelmente, muitas dúvidas e questionamentos vieram à tona mediante este drama. Objetivamos demonstrar que os questionamentos teológicos fomentados pelo atual Sumo Pontífice possibilitam não somente um dialogar com a situação humana atual, mas também apontam saídas para salvar e dar qualidade de vida a todas as criaturas. Do ponto de vista formal, indaga-se: é possível pensar teologicamente a pandemia à luz de alguns escritos do Papa Francisco? Trata-se de uma pesquisa bibliográfica embasada em alguns pronunciamentos e escritos do Papa, cujos resultados esperados circunscrevem-se ao fato de entendermos que ele busca sempre atribuir um sentido à vida oferecendo elementos que possibilitam uma qualificada formação humana integral. Desse modo, argumenta-se que os resultados esperados serão de que, mediante a leitura de Francisco, as pessoas têm a oportunidade de saírem da pandemia mais humanizadas, contribuindo assim, para que o mundo eivado de crises humanitárias, políticas, sanitárias, econômicas, religiosas e ecológicas, seja mais saudável.

Palavras-chaves: Teologia. Pandemia. Papa Francisco. Cruz-ressurreição. Esperança. 


\begin{abstract}
From some writings of Pope Francis, we realize that it is possible to think theologically about the pandemic. It is noted that, paradoxically, the uncertainties caused by the coronavirus pandemic tragedy can put the human being in the direction of a new way of life. Inevitably, many doubts and questions surfaced because of this drama. We aim to demonstrate that the theological questions fostered by the current Supreme Pontiff allow not only a dialogue with the current human situation, but also point out ways to save and give quality of life to all creatures. From a formal point of view, the question is: is it possible to think theologically about the pandemic in the light of some writings of Pope Francis? This is a bibliographical research based on some pronouncements and writings of the Pope, whose expected results are limited to the fact that we understand that he always seeks to give meaning to life, offering elements that enable a qualified integral human formation. Thus, it is argued that the expected results will be that, by reading Francisco, people have the opportunity to leave the pandemic more humanized, thus contributing to a world riddled with humanitarian, political, sanitary, economic crises, religious and ecological, be healthier.
\end{abstract}

Keywords: Theology. Pandemic. Pope Francis. Cross-resurrection. Hope.

\title{
Introdução
}

Em meio a tantos desalentos, e, no desafio de refletir sobre Teologia e pandemia, indagamos: quais são as luzes captadas e emitidas pelos escritos do Papa Francisco neste tempo de pandemia? Entendemos que esta é uma pergunta bastante ampla, mas recorrente e decisiva para o ser humano, já que não diz respeito a alguma situação pontual, mas à sua existência como um todo. As possíveis respostas até aqui para a cura e santificação da humanidade e do planeta se mostraram insuficientes. Procuramos, então, nos escritos de Francisco uma palavra iluminadora da Teologia que emana do seu pensamento. Como um recorte teórico, recorremos principalmente, à encíclica Laudato Sí; à mensagem Urbi et orbi, celebração solene durante o momento extraordinário de oração em tempo de epidemia, realizada em 27 de março de 2020; à Fratelli Tutti; Às Bem-Aventuranças e a Cura do Mundo e também à Exortação 
Apostólica Querida Amazônia. Através destes documentos dialogaremos com outros autores em busca de uma reflexão que consideramos relevante para iluminar o nebuloso tempo atual.

Partiremos de uma contextualização e problematizações no horizonte da Pandemia e Teologia para um melhor entendimento daquilo que pode estar por detrás e no princípio da pandemia, ou seja, das outras "pandemias" consumismo, descarte humano e ecológico, indiferenças etc. - que nasceram a partir do descuido com a vida, como veremos no segundo item deste artigo. Em seguida adentraremos nos documentos supracitados para "pinçar" elementos indicados a norteadores do agir humano na atual crise. Buscaremos chegar ao entendimento de como será possível alimentar a esperança diante da "demência humana" em uma pandemia como a Covid-19.

Atingir tais objetivos já se torna um grande desafio. Desse modo, objetivamos demonstrar, também, que o compromisso da Teologia não é apenas dialogar com a situação humana atual, mas faz parte da sua natureza científica, a busca de saídas para salvar e apontar caminhos norteadores da qualidade de vida para todos as criaturas. Em face disso, a partir de alguns escritos do Papa Francisco, entende-se que é no reconhecimento de todos os seres como obras criadas e amadas por Deus que se pode valorizar a vida e lhe favorecer uma melhor qualidade sempre.

É evidente que a sua Teologia não pretende dar respostas fáceis ou fechadas às calamidades que costumam acontecer. Contudo, como ciência que se debruça sobre o sentido da existência, ela será sempre desafiada a fomentar uma reflexão frente a tais situações no intuito de contribuir para o bem da vida no planeta. Nesse sentido, a expressão theo-loghia, que, literalmente quer dizer "palavra sobre Deus", ou seja, uma mensagem divina, desabrocha como chave de leitura para este momento. Como a "criação é um grito articulado por um Criador. A Teologia nada mais faz senão recolher esse grito e articulálo racionalmente". ${ }^{1} \mathrm{E}$, com este vírus se espalhando por todos os cantos do planeta, se ouve um grito da humanidade pedindo por uma luz, clamando por uma saída. Carregado de uma Teologia portadora de esperança por excelência, entendemos que os escritos do Papa Francisco possibilitam ao leitor entrar em contato com o mistério divino, de modo que eles facilitam uma melhor revelação do amor misericordioso de Deus à humanidade. Os seus escritos são férteis de uma intensa mensagem que contém as virtudes teologais. De

${ }^{1}$ BOFF, C., Conselhos a um jovem teólogo, p. 78. 
modo que, no anúncio do Reino de Deus, ele fortalece a fé e a esperança, apontando para a verdadeira prática da caridade. "Um reino de justiça e paz que se manifesta através de obras de caridade que, por sua vez, aumenta a esperança e fortalecem a fé". ${ }^{2}$ A presente reflexão se propõe em busca de tal novidade, sem descuidar da necessária análise de conjuntura para, assim, anunciar o tempo futuro, que é talhado pela esperança cristã.

\title{
1. Pandemia e Teologia: contextualização e problematizações
}

\author{
"Se o senhor quiser fazer-me um favor, \\ se lhe parecer bom, o meu pedido é que me conceda a vida, \\ e o meu desejo é a vida do meu povo" (Est 7,3).
}

Diante das inúmeras problematizações acerca da pandemia, analogicamente nos questionamos: como trocar o pneu de um carro em movimento? Como dar assistência técnica ao avião enquanto ele está no ar? E ainda mais no momento de uma forte turbulência? Este é exatamente o "clima" em que a presente reflexão é gestada. Em relação à pandemia do coronavírus, de todas as certezas, aquilo que se tem, no atual cenário, são dúvidas, muitas dúvidas. E, qualquer tentativa de ponderação parece obsoleta no dia seguinte. Respondendo às indagações iniciais, relacionando-as ao tempo atual, sabemos que o que não se pode é parar e cruzar os braços. O tempo urge e é preciso conter este terrível mal que ceifa tantas vidas. Como é natural e óbvio, a vida não para, assim como o tempo e o planeta também não param, ou seja, não é possível parar o planeta terra e leválo em uma oficina ou um hospital. A terra continua seguindo a sua trajetória e precisamos refletir como a Teologia pode nos ajudar a continuar o percurso. Se faz urgente que o ser humano continue repensando a criação e reestabelecendo a paz com a mãe terra, em meio a atual pandemia. Resta-lhe infundir esperanças e forças. Em meio à turbulência do presente há também uma certa acédia que paralisa as ações humanas, de modo que "alguns resistem até ao fundo o gosto da missão e acabam mergulhados em uma acédia paralisadora". ${ }^{3}$

No momento em que este texto é redigido, aqui no Brasil, estamos passando por uma assombrosa gravidade e mortalidade que se soma às sequelas de dois anos de pessoas acometidas pelo vírus Covid19. Amedrontadoramente, assistimos aos noticiários de que vidas são ceifadas incontroladamente, sistema

\footnotetext{
${ }^{2}$ FRANCISCO, PP., As bem-aventuranças e a cura do mundo, p. 41.

${ }^{3}$ EG 81.
} 
de saúde e funerário em colapsos. Se, a vida em abundância é o que Deus quer para os seus filhos (Jo 10,10) e a nossa percepção da atual situação é a de que a vida está sendo banalizada no mais alto nível, nos questionamos: como é possível dormir tranquilamente quando se têm consciência desta verdade de fé advinda do testemunho das Sagradas Escrituras e ver acontecer justamente o contrário? Frente a esta pandemia, talvez tanto quanto os médicos(as) e enfermeiros(as), - que, como se sabe, ao tentarem dormir, lhes ressoam as imagens de horrores e sofrimentos -, também os teólogos são desafiados e arremetidos ao mesmo cenário pela própria percepção que têm. "A pandemia pôs em evidência quão vulneráveis e interligados estamos todos nós. Se não nos preocuparmos uns com os outros, a começar pelos últimos, por aqueles que são mais atingidos, incluindo a criação, não podemos curar o mundo". ${ }^{4}$ O sentimento de impotência habita o nosso interior, e, com todos os esforços reunidos, ao longo destes tempos, procurarmos emitir mensagens de esperanças, de encorajamento e de conscientização por todos os meios possíveis. "Durante décadas, pareceu que o mundo tinha aprendido com tantas guerras e fracassos e, lentamente, foi caminhando para várias formas de integração. (...). Mas a história dá sinais de regressão. Reacendem-se conflitos anacrônicos que se consideravam superados, ressurgem nacionalismos fechados, exacerbados e ressentimentos agressivos". ${ }^{5}$ A partir do princípio da cruz e da ressurreição, argumentamos que é sempre necessário cultivar a esperança apesar do mal, focando na ressurreição como horizonte. Graça à força advinda da esperança cristã, somos desafiados a:

Encarar as dificuldades que a concepção de princípio tem de enfrentar ao se traduzir na vida dos indivíduos e na história dos povos. Sobretudo, diante da grande e terrível experiência do mal, que com suas dores e irrefutáveis arestas ameaça reduzir à mera especulação teórica ou à simples projeção desiderativa todo o discurso da esperança. Creio que o cristianismo, sobretudo graças à dialética cruz-ressurreição, tem em sua tradição uma resposta que pode abrir os melhores horizontes. ${ }^{6}$

Assim, o teólogo sabe que é preciso evidenciar, sem cessar, a força da esperança apesar do mal que nos rodeia. É urgente lutarmos juntos para

\footnotetext{
${ }^{4}$ FRANCISCO, PP., As bem-aventuranças e a cura do mundo, p. 45.

${ }^{5}$ FT 10-11.

${ }^{6}$ QUEIRUGA, A. T., A esperança apesar do mal, p. 11.
} 
que todos tenham vida. Como portadores da esperança cristã e também denunciadores das injustiças, é um dever que se impõe, na atual conjuntura, a todos os teólogos. "Ai de mim se eu não anunciar o Evangelho" (1Cor 9,16) e denunciar injustiças: "Ai daqueles que juntam casa com casa e emendam campo a campo, até que não sobre mais espaço e sejam os únicos a habitarem no meio do país" (Is 5,8). Que profecia a Teologia está exercendo, no período da pandemia, quando tantos morrem de fome, enquanto outros vivem à base de vinhos e queijos? A serviço de quem está a profecia? Que denúncia de injustiça e anúncio de esperança apregoa hoje a Teologia? Que protagonismo há hoje a ação teológica perante a história da salvação devastada pela pandemia? Sabese que, essencialmente, a teologia cristã é portadora de esperanças e a isso ela não pode perder de vista sob pena de ser inócua. Entende-se que, apesar dos sinais de morte, "a esperança não nos decepciona" (Rm 5,5), pois "ainda que eu ande pelo vale tenebroso, nenhum mal eu temerei, estais comigo" (S1 23,4 ), disso o teólogo tem elementar consciência ou, ao menos tecnicamente deveria ter. E, se tem, como tem evidenciado a sua contribuição? As questões eclodem com abundância. Estas aqui suscitadas, entendemos que são apenas a ponta do iceberg.

Contudo, em face à "banalidade do mal", 7 sabemos também que há a transcendência do bem, ${ }^{8}$ como o exemplo das "dioceses do Brasil que oferecem espaços da Igreja como hospitais de campanha". ${ }^{9}$ Borbulham tantos outros exemplos de bem, recordamos uma agradável visita ao Bispo Dom Arnaldo Carvalheiro, de Itapeva/SP, que nos contava sobre a sua atitude de deixar a sua casa disponível aos idosos do asilo São Vicente e ir para o seminário

\footnotetext{
${ }^{7}$ ARENDT, H., Eichmann em Jerusalém, p. 3. A expressão banalidade do mal tem a sua inspiração na obra da filósofa Hanna Arendt que, segundo ela, "muitos ainda julgam que a ideologia nazista girou em torno do antissemitismo por acaso, e que desse acaso nasceu a política que inflexivamente visou perseguir e, finalmente, exterminar os judeus". (ARENDT, H., Origens do totalitarismo, p. 25), contudo, se sabe que nada foi por acaso. Da mesma forma que hoje o extermínio de tantas pessoas nesta pandemia no Brasil, não é por acaso, mas uma necropolítica [política de morte/extermínios] em cujos interesses da defesa da vida são negligenciados atualmente no Brasil, piadística e escancaradamente, por alguns que têm o dever de agir para impedir tantas mortes, especialmente dos mais vulneráveis.

${ }^{8}$ A expressão transcendência do bem remete às atitudes que exalta e reluz o bem, isto é, as boas ações em favor da vida digna para todos. O sentido aqui empregado é exatamente a do "Absoluto [que] aparece na figura do Bem Supremo e do Uno, que fundamenta sem ser fundamentado, todo ser finito e, por conseguinte, o transcende, está além do ser. (...). Deus deixa de ser objeto da vista e se converte no próprio 'ver' que não é visto, mas que faz ver" (SÁNCHEZ, J. J., Absoluto, p.1).

${ }^{9} \mathrm{CNBB}$, Arquidioceses do Brasil oferecem espaços da Igreja como hospitais de campanha.
} 
durante um período da pandemia. Isso porque alguns idosos tinham contraído o Covid-19 e os demais precisavam de um novo local seguro. Podemos ainda citar tantos exemplos de jovens que oferecem aos vizinhos idosos a possibilidade de fazer as suas compras nos supermercados ou farmácias. Porém, apesar disso, o sentimento é de que é preciso ir além. De frente ao descaso da realidade sanitária mundial e, do Brasil em particular, tudo ainda parece estar muito aquém do necessário.

Mas sabemos que entre o bem e o mal existe uma linha muito tênue, de pouco limites tangíveis, de modo que alguns querem o bem, mas fazem o mal. "Não faço o bem que quero, e sim o mal que não quero" $(\mathrm{Rm} 7,19)$ isso, em certo limite é inerente à fragilidade humana. Neste dilema, se evidencia, por um lado, a sensatez de alguns, mas também a demência de outros. Neste último grupo, por irresponsabilidade, destacam-se autoridades eleitas que se eximem da responsabilidade que lhes fora confiada e seus apoiadores eivados de fanatismos. Mas, em face disso, atônitos, indagamos: por que essa demência ou degeneração humana? Por que tanta dificuldade de as pessoas adotarem uma disciplina ou uma contribuição coletiva diante da gravidade do momento? Não seria perceptível a necessidade de viver a privação de alguns bens em vista do bem maior, a vida de todos? A defesa da vida não justifica renunciar às festas, ao esporte? Isso parece algo absurdo? E, paradoxalmente, mergulhados neste absurdo entramos na desvalorização da vida de modo banal e insano. Parece que vale mais se divertir ou realizar os desejos egoístas do que pensar no bem público e coletivo. Entendemos que a Teologia precisa ajudar a sociedade a ocupar a cena pública e dar um basta nas inúmeras negligências, seja de governantes, seja da população mesma que, perversamente, desrespeita o princípio até da própria vida em nome de uma falsa liberdade.

O argumento é simples: sem vida não se pode falar em liberdade, embora seja possível, com a privação de liberdade, valorizar a vida (...). O debate entre a vida e a liberdade é perverso. A perversidade está na impossibilidade de escolha de uma ou outra posição para a maioria do povo brasileiro em se tratando do coronavírus. (...). Destaque da perversidade: de um lado há pessoas que não podem ficar em casa por necessidade de sobrevivência. De outro, pessoas que poderiam ficar em casa optam por espalhar o vírus. Como sensibilizar este segundo grupo social de que a vida antecede a liberdade? Eis a pergunta de um milhão de reais..$^{10}$

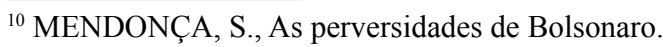


$\mathrm{Na}$ atual conjuntura brasileira, altamente eivada de uma polarização político-religiosa se vê, por todos os lados, religiosos se utilizando do fanatismo para defender e atacar posições distintas em relação aos decretos de controle do coronavírus. Isso evidencia a desconexão por parte de um setor da Igreja com a vida concreta da sociedade. Se vê que se perdeu o foco daquilo que é essencial, a defesa da vida, e precisamos urgentemente rever posições e retomar o caminho do seguimento de Jesus, a partir do seu seguimento testemunhal, adotando o percurso de compromisso com a vida digna. Se não há protagonismo e uma posição uníssona na defesa da vida digna para todos, o ensinamento evangélico (Jo 10,10) precisa ser retomado, evidenciado e seguido. Em face de tantos negacionismos, argumenta-se que defender a vida não é um gosto pessoal, é um dever ético. Vacinar-se, por exemplo, não é um desejo ou um gosto pessoal, é uma questão de responsabilidade coletiva, sem contar que no Brasil é um dever legal. ${ }^{11}$ Tratar bem o outro não é uma opção, mas um dever que se impõe e isso precisa ser recordado e cobrado com todas as forças e por todas as instâncias. A esse respeito, o próprio Papa Francisco pondera que vacinar "é uma escolha ética porque estamos a falar da saúde da sua vida, mas também da vida de outras pessoas". ${ }^{12}$

Observa-se que diante de uma democracia fragmentada e de uma sociedade dilacerada, os religiosos que deveriam viver o testemunho evangélico da comunhão e da sinodalidade, acabam adotando uma polaridade vergonhosa num espírito espartano de rivalidades sem fim. Seguimos hoje uma grotesca lógica do ataque tanto de modo sutil quanto brutal, de uma política de denuncismos desumano e deletério. Sem necessidade de muitas ponderações, mas só a título de exemplo, as polêmicas evidenciadas pelo tema da Campanha da Fraternidade 2021, em pleno desastre pandêmico, são reveladoras de onde

\footnotetext{
${ }^{11}$ Vale ressaltar que: "o movimento anti vacinação é forte no Brasil, e o especialista em Direitos Humanos e em Ciências Jurídico-Filosóficas pela Universidade de Coimbra e professor de Direito Constitucional e Administrativo no Meu Curso, Daniel Lamounier, alerta que a futura imunização contra o Covid-19 não é uma questão de liberdade pessoal, e sim de saúde pública, tanto nacional quanto mundial. "A vacinação obrigatória tem previsão legal desde 1975, na lei de 6259. A vacinação obrigatória acontece porque a vacinação de apenas alguns indivíduos não causaria o efeito de imunização, já que a própria vacina, como regra, não tem o poder de imunizar mais que $70 \%$ na nossa média das pessoas. Então se não houver imunização em bloco, o vírus vai continuar circulando", explica, um efeito não só da futura vacina da Covid-19 como qualquer imunizante de massa. PORTAL HOSPITAIS BRASIL, Vacinação obrigatória tem respaldo na lei e governo pode exigir imunização contra a Covid-19.

12 VOA PORTUGUÊS, Papa Francisco diz que decisão de receber a vacina COVID é uma questão ética.
} 
está o foco das preocupações de algumas facetas de religiosos, que, eivados dos fanatismos políticos e religiosos de modalidade ultraconservadoras, evidenciam interesses escusos aí atrelados. Como profetas do templo, fazem vistas grossas e ataques àqueles que ousam adotar uma atitude de defensores da vida. E neste jogo sujo e doentio, nem o Papa, sai ileso. Para visualizar tal situação, basta conferir qualquer postagem da própria CNBB. O conhecido fogo amigo aí está presente. E, tristemente sabemos que "um reino dividido se esfacela" (Mt 12,25).

Ainda em caráter de contextualização, vamos retomar a pergunta perturbadora do Papa Francisco na Laudato Si”: “o que está acontecendo com nossa casa?"13 Diante desta questão ele propõe seis pontos de reflexão "não para recolher informações ou satisfazer a nossa curiosidade, mas para tomar a dolorosa consciência, ousar transformar em sofrimento pessoal aquilo que acontece ao mundo e, assim, reconhecer a contribuição que cada um lhe pode dar". ${ }^{14}$ O Sumo Pontífice reflete sobre a poluição e mudanças climáticas, ${ }^{15}$ a questão da água, ${ }^{16}$ a perda da biodiversidade, ${ }^{17}$ a deterioração da qualidade de vida humana e degradação social, ${ }^{18}$ desigualdade planetária, ${ }^{19}$ a fraqueza das reações, ${ }^{20}$ diversidade de opiniões. ${ }^{21}$ Não desenvolveremos uma longa discussão sobre tais temas, já que o Santo Padre os fez com tanta profundidade, mas procuramos elencá-los e ligá-los no decorrer do presente texto.

Numa palavra, a reflexão sobre Pandemia e Teologia nos obriga a trazer essa contextualização e problematizações para vislumbrarmos um horizonte mais palpável e possível a fim de que a vida seja respeitada e defendida. Temos consciência que, quanto mais refletirmos sobre estas desafiadoras realidades, tanto mais teremos chances de avançar. Seguiremos ainda alguns traços de uma reflexão provocativa sobre outras pandemias que, tristemente, devastam a humanidade, de modo silencioso.

\footnotetext{
${ }^{13}$ LS 17.

${ }^{14}$ LS 19.

${ }^{15}$ LS 20-26.

${ }^{16}$ LS 27-31.

${ }^{17}$ LS 32-42.

${ }^{18}$ LS 43-47.

${ }^{19}$ LS 48-52.

${ }^{20}$ LS 53-59.

${ }^{21}$ LS 60-61.
} 


\section{Por detrás e além do coronavírus: as demais pandemias}

Indubitavelmente a atual crise sanitária global, gerada pela pandemia do coronavírus, exige soluções que ajudem a superar os grandes desafios da humanidade. Para tanto, torna-se indispensável um olhar atento para os sinais evidentes a que a mãe terra nos oferece. Nesse sentido, antes mesmo desta pandemia, o planeta já demonstrava que não estava tudo bem, mas que agonizava em diversos aspectos - poluição hídrica e atmosférica, poluição da terra, derrubada das árvores, causando a extinção de milhões de espécies, as fúrias das tempestades, o aquecimento global sem controle etc. A terra foi dando sinais de esgotamento de sua riqueza, ou seja, mostrando que não possui recursos naturais inesgotáveis e por isso, precisava, como todo ser vivo, de novos cuidados. O ser humano que foi colocado no meio do jardim para cuidar e guardar (Gn 2,8), acabou confundindo seu papel de cuidar e guardar para uma prática da exploração irresponsável e, em face disso, “o Papa Francisco operou uma grande virada no discurso ecológico ao passar da ecologia ambiental para a ecologia integral. Esta inclui a ecologia políticosocial, a mental, a cultural, a educacional, a ética cultural. (...) Como superar a perigosa rota de colisão entre ser humano e a natureza?"22 $\mathrm{O}$ ser humano precisa entender que é parte da natureza, mas com a responsabilidade ética de guardar e cuidar sem esquecer da lógica da cominação antropocêntrica.

As dores da mãe terra nos dão conta de que a trajetória atual, de erosão da biodiversidade, nos encaminha para o caos.

Ninguém, nem o papa nem o Dalai-Lama, nem algum sábio saído dos grandes centros que acompanham sistematicamente o estado da Terra pronunciam uma palavra segura. Estamos num voo cego com a esperança de que não seremos levados a um choque contra alguma montanha. Mesmo assim, cremos e esperamos que as dores do tempo presente não signifiquem os estertores de um moribundo, mas as dores de parto de um outro tipo de mundo que nos permita ainda viver neste pequeno e belo Planeta Terra. ${ }^{23}$

Entre tantas manifestações globais, referentes ao andamento da situação do planeta terra e sobre a difusão do coronavírus, vemos que já nos primeiros

\footnotetext{
${ }^{22}$ BOFF, L., A encíclica do Papa Francisco não é “verde”, é integral, p. 19.

${ }^{23}$ BOFF, L., A terra na palma da mão, p. 9.
} 
momentos da pandemia, Papa Francisco se mostrou preocupado com a situação pandêmica, principalmente, atento às pessoas que mais sofriam com todos os problemas decorrentes do vírus. Em seus pronunciamentos foi nos mostrando que já tinha alertado a humanidade para catástrofes provocadas pela avidez na exploração, na produção e consumo. As catástrofes maiores poderiam ser eminentes, decorrentes, também, de ações humanas, principalmente na falha com o cuidado da mãe terra.

Falhamos na nossa responsabilidade de guardiães e administradores da Terra. Basta olhar a realidade com sinceridade para ver que há uma grande deterioração da nossa casa comum (LS 61). Poluímo-la, saqueámo-la, colocando em perigo a nossa própria vida [...]. Não há futuro para nós se destruirmos o meio ambiente que nos sustenta. ${ }^{24}$

São dois pontos importantes e inseparáveis, no pensamento de Francisco, quando trata do cuidado com a Terra. Deve-se notar que "uma verdadeira abordagem ecológica sempre se torna uma abordagem social, que deve integrar a justiça nos debates sobre o meio ambiente, para ouvir tanto o clamor da terra como o clamor dos pobres". ${ }^{25}$ Destruir o meio ambiente é destruir a própria humanidade. Essa destruição, que se manifesta através da derrubada de árvores para a produção de soja ou para o plantio de pasto para o gado, é fruto de outras atitudes humanas que podem ser vistas como pandemias, pois está afetando grande parte das pessoas neste mundo.

Sendo assim, para além da pandemia do coronavírus, percebe-se outras pandemias que assolaram e continuam assolando a humanidade e trazendo consigo consequências drásticas que se somam a estas do Covid-19. Pensamos no consumismo que o Santo Padre denunciou inúmeras vezes: "Quando se vive para as coisas, as coisas nunca são suficientes, a ganância cresce e os outros tornam-se obstáculos na corrida; no final, todos se sentem ameaçados e, sempre insatisfeitos e com raiva, aumenta o nível de ódio". ${ }^{26}$ Podemos citar o vírus do descarte, pois "partes da humanidade parecem sacrificáveis em benefício duma seleção que favorece a um setor humano digno de viver sem limites". ${ }^{27} \mathrm{Na}$ lógica do descarte, as pessoas sacrificáveis são aquelas que já

\footnotetext{
${ }^{24}$ FRANCISCO, PP., Catequese por ocasião do $50^{\circ}$ Dia Mundial da Terra.

${ }^{25}$ LS 45.

${ }^{26}$ AGÊNCIA ECCLESIA, Vaticano.

${ }^{27}$ FT 18.
} 
não representam mais lucros para a sociedade. "No fundo, as pessoas já não são vistas como um valor primário a respeitar e tutelar, especialmente se são pobres ou deficientes, se 'ainda não servem' (como os nascituros) ou 'já não servem mais' (como os idosos)". ${ }^{28}$ Podemos entender, também, que, como um vírus, o poder e a ambição que nascem da tecnologia: "Não podemos, porém, ignorar que a energia nuclear, a biotecnologia, a informática, o conhecimento do nosso próprio DNA e outras potencialidades que adquirimos, nos dão um poder tremendo", ${ }^{29}$ no entanto, o Papa nos alerta que este poder é detido por alguns que dominam o conjunto do gênero humano: "Nunca a humanidade teve tanto poder sobre si mesma, e nada garante que o utilizará bem, sobretudo se se considera a maneira como o está fazendo". ${ }^{30}$ Ainda outro exemplo de pandemia que cresce na humanidade é o paradigma tecnocrático, ou seja, o modo como "a humanidade assumiu a tecnologia e o seu desenvolvimento (...) com a ideia de um crescimento infinito ou ilimitado, (...). Isto supõe a mentira da disponibilidade infinita dos bens do planeta". ${ }^{31}$

Certamente terão tantas outras pandemias em nosso tempo se o ritmo do egoísmo humano não for refreado e se não mudarmos os hábitos hodiernos. Papa Francisco se torna um crítico desta realidade. Isso não revela uma imagem de ser humano negativo ou pessimista, mas aponta um humano atento à realidade. Mais do que curioso, ele é consciente da realidade e corajoso na luta pela sua transformação.

Na linha do Papa Francisco, o Cardeal José Tolentino Mendonça faz uma oração muito consciente de tantos vírus presentes em nosso meio:

Livra-nos, Senhor, deste vírus, mas também de todos os outros que se escondem dentro dele. Livra-nos do vírus do pânico disseminado, que em vez de construir sabedoria nos atira desamparados para o labirinto da angústia. Livra-nos do vírus do desânimo que nos retira a fortaleza de alma com que melhor se enfrentam as horas difíceis. Livra-nos do vírus do pessimismo, pois não nos deixa ver que, se não pudermos abrir a porta, temos ainda possiblidade de abrir janelas. Livra-nos do vírus do isolamento interior que desagrega, pois o mundo continua a ser uma comunidade viva. Livra-nos do vírus do individualismo que faz crescer

\footnotetext{
${ }^{28}$ FT 18.

${ }^{29}$ LS 104.

${ }^{30}$ LS 104.

${ }^{31} \mathrm{LS} 106$.
} 
as muralhas, mas explode em nosso redor todas as pontes. Livra-nos do vírus da comunicação vazia em doses massivas, pois essa se sobrepõe à verdade das palavras que nos chegam do silêncio. Livra-nos do vírus da impotência, pois uma das coisas mais urgentes a aprender é o poder da nossa vulnerabilidade. Livra-nos, Senhor, do vírus das noites sem fim, pois não deixas de recordar que Tu Mesmo nos colocaste como sentinelas da aurora. $^{32}$

Certamente essas são pandemias que vem sendo gestadas a longo prazo. Que tocam a humanidade sem nem mesmo percebê-las. Mas podemos afirmar que "o risco é que nos atinja um vírus ainda pior: o da indiferença egoísta. Transmite-se a partir da ideia de que a vida melhora se vai melhor para mim, que tudo correrá bem se correr bem para mim". ${ }^{33}$ Com este tipo de mentalidade, em qualquer tempo, a indiferença egoísta faz crescer grandes pandemias. Isso precisa mudar, mediante um novo jeito de viver.

É evidente a necessidade de unirmos esforços e remarmos para a mesma saída, na urgente busca de superação da pandemia do coronavírus, mas também das demais pandemias que se escondem no desejo de viver bem em vez do "bem-viver" coletivo. É necessário reconhecer nossa interligação, principalmente neste momento vulnerável. Vale reconhecer a coragem, a determinação e o sentimento de fraternidade universal em passos largos na defesa incondicional da vida durante esses meses sofridos.

\section{A Laudato Sí já era uma premonição do eminente risco de extinção em massa?}

Já no início da Carta Encíclica Laudato Si', o Papa Francisco nos recorda que a nossa casa comum "se pode comparar ora a uma irmã, com quem partilhamos a existência, ora a uma boa mãe, que nos acolhe nos seus braços" ${ }^{34}$ No entanto, "esta irmã clama contra o mal que lhe provocamos por causa do uso irresponsável e do abuso dos bens que Deus nela colocou". ${ }^{35}$ Esta atitude humana é fruto de um modelo educativo que nos roubou a consciência de irmandade e de filiação, e nos fez "pensar que éramos seus

\footnotetext{
${ }^{32}$ MENDONÇA, J. T., Livra-nos deste vírus e de todos os outros.

${ }^{33}$ FRANCISCO, PP., Vida após pandemia, p. 54.

${ }^{34}$ LS 1.

${ }^{35}$ LS 2.
} 
proprietários e dominadores, autorizados a saqueá-la" ${ }^{36}$ Rememorando São Paulo VI, o atual pontífice fala de uma crise como "consequência dramática da atividade descontrolada do ser humano". ${ }^{37}$ Esta atividade exploratória leva ao risco de destruir a natureza e de ser "vítima dessa degradação". ${ }^{38}$ Citando ainda São Paulo VI, e evidenciado a possibilidade de uma catástrofe ecológica assim admoesta: “os progressos científicos mais extraordinários, as invenções técnicas mais assombrosas, o desenvolvimento econômico mais prodigioso, se não estiverem unidos a um progresso social e moral, voltam-se necessariamente contra o homem". ${ }^{39}$

Após fundamentar-se em São Paulo VI, o Papa Francisco também apresenta elementos dos seus antecessores, São João Paulo II e Bento XVI, para demonstrar que esta preocupação já era recorrente nos documentos e pronunciamentos dos sumos pontífices. Mas não era apenas uma preocupação eclesial, já que tantos cientistas, líderes políticos e religiosos não católicos também manifestaram grandes preocupações com o futuro do planeta e, consequentemente com a vida humana. No entanto, apesar de tantas alertas, agora é urgente dar outro passo, ainda mais cuidadoso e profundo: partir do reconhecimento da grandeza, urgência e beleza da natureza, sem se esquecer dos vários aspectos da atual crise ecológica, para assumir os melhores frutos da pesquisa científica atualmente disponível deixando tocar-se por ela. $\mathrm{O}$ Papa admoesta que é preciso: "chegar às raízes da situação atual, de modo a individuar não apenas os seus sintomas, mas também as causas mais profundas (...), propor uma ecologia que, nas suas várias dimensões, integre o lugar específico que o ser humano ocupa neste mundo e as suas relações com a realidade que o rodeia". ${ }^{40}$

Se olharmos a estrutura da Encíclica Laudato Si', perceberemos que Francisco parte do "Cântico das criaturas" de São Francisco de Assis, das preocupações dos Papas anteriores, das vozes de outras pessoas não católicas e do seu próprio apelo sobre a terra. O seu jeito de falar demonstra que o ponto de partida para a melhoria dos problemas do presente não é a denúncia, mas o reconhecimento histórico da beleza ecológica, além de reconhecer também os seus limites. O segundo ponto tratado nessa encíclica é uma análise do "que

\footnotetext{
${ }^{36} \operatorname{LS} 2$.

${ }^{37}$ LS 4.

${ }^{38} \mathrm{LS} 4$.

${ }^{39}$ LS 4.

${ }^{40}$ LS 15.
} 
está acontecendo com nossa casa", ${ }^{41}$ neste capítulo é visível a denúncia do descuido, do saqueamento e da destruição da casa comum.

A terra, nossa casa, parece transformar-se cada vez mais num imenso depósito de lixo. Em muitos lugares do planeta, os idosos recordam com saudade as paisagens de outrora, que agora veem submersas de lixo. Tanto os resíduos industriais como os produtos químicos utilizados nas cidades e nos campos podem produzir um efeito de bioacumulação nos organismos dos moradores nas áreas limítrofes, que se verifica mesmo quando é baixo o nível de presença de um elemento tóxico num lugar. Muitas vezes só se adotam medidas quando já se produziram efeitos irreversíveis na saúde das pessoas. ${ }^{42}$

A partir deste olhar atento sobre a realidade, o Papa oferece elementos teológicos mais profundos sobre o planeta terra. Ele o chama de "O Evangelho da criação". ${ }^{43}$ É com este olhar que entra na raiz humana da crise ecológica e dela extrai pontos essenciais para o capítulo sucessivo que é o fomento de uma ecologia integral, no qual demonstra que a ecologia não é separada do humano, mas é integral. Os dois últimos capítulos são linhas de orientação e ação, vivendo uma educação e espiritualidade ecológica.

O leque de pontos tratados na encíclica não são uma premonição para dizer o que a humanidade estava prestes a viver: pandemia do coronavírus, mas sim um olhar enraizado na situação presente e indicações concretas da necessidade de mudanças de rumo. Se, por um lado, a situação atual favorece formas de egoísmo coletivo, tornando as pessoas autorreferenciais e isoladas na própria consciência, aumentando, assim, a sua voracidade: "quanto mais vazio está o coração da pessoa, tanto mais necessita de objetos para comprar, possuir e consumir". ${ }^{44}$ No entanto, por outro lado, está a possibilidade de regeneração. As pessoas "são capazes de olhar para si mesmos com honestidade, externar o próprio pesar e encetar caminhos novos rumo à verdadeira liberdade. Não há sistemas que anulem, por completo, a abertura ao bem, à verdade e à beleza". ${ }^{45}$

Este olhar consciente dos dois lados da realidade, o sombrio e o luminoso, ajuda a humanidade a tomar consciência da sua responsabilidade. Nota-se que

\footnotetext{
${ }^{41}$ LS 20-42.

${ }^{42}$ LS 21.

${ }^{43}$ FRANCISCO, PP., Vida após pandemia, p. 61.

${ }^{44}$ LS 204.

${ }^{45}$ LS 204.
} 
a Laudato $S i$ ', que é desenvolvida a partir de uma situação em que a terra grita e pede para ser ouvida, ressalta uma preocupação que se estenderá às gerações futuras. O tempo da mudança é agora, mas sabemos que isso leva uma geração. O lugar da atuação é o planeta, no entanto, têm lugares pontuais que precisam, com urgência de mais cuidado:

Há lugares que requerem um cuidado particular pela sua enorme importância para o ecossistema mundial, ou que constituem significativas reservas de água, assegurando assim outras formas de vida. Mencionemos, por exemplo, os pulmões do planeta repletos de biodiversidade, que são a Amazônia e a bacia fluvial do Congo, ou os grandes lençóis freáticos e os glaciares. A importância destes lugares para o conjunto do planeta e para o futuro da humanidade não se pode ignorar. Os ecossistemas das florestas tropicais possuem uma biodiversidade de enorme complexidade, quase impossível de conhecer completamente, mas, quando estas florestas são queimadas ou derrubadas para desenvolver cultivos, em poucos anos perdem-se inúmeras espécies, ou essas áreas transformam-se em áridos desertos. ${ }^{46}$

Com este cuidado, Francisco ajuda a superar aquela ideia religiosa, ainda arraigada na mentalidade popular, de um “'deus-senhor' que de fora governa seus domínios, que manda por decreto, que age como e quando bem entender, e que, se solicitado, atende quando the parecer bem (...). As relações com ele seja o de servi-lo no que se lhe deve, o de convencê-lo no que nos convém, o de esperar o prêmio ou temer o castigo". ${ }^{47}$ Portanto, a encíclica está longe da possibilidade de ser ou de fazer premonições. Está muito mais preocupada com a superação da ideia distorcida de um Deus inimigo do progresso e da felicidade humana. É um documento revelador da presença divina na beleza natural de todos os seres e um convite ao cuidado responsável. Admoesta que, se destruirmos avidamente os seres vivos, quebramos a corrente natural da evolução da vida e nos tornamos destruidores da nossa própria casa. Mas, se reconhecermos a beleza de cada ser, a sua vocação e a sua sacralidade, iremos formar uma comunhão de cuidado e de progresso sustentável para o nosso planeta e a continuidade da vida.

\footnotetext{
${ }^{46}$ LS 37-38.

${ }^{47}$ QUEIRUGA, A. T., Recuperar a criação, p. 116.
} 


\title{
4. O Sínodo para a Amazônia e a Exortação "Querida Amazônia" como convite ao sonho de uma nova relação com a casa comum
}

Nota-se que nem o Sínodo dos Bispos para a Amazônia, nem o documento Querida Amazônia tratou diretamente sobre questões pandêmicas. No entanto, eles nos ajudam a compreender a relação humana com a Terra, percebendo que a situação da pandemia da Covid-19 é um sinalizador de que o Planeta Terra está enfermo. Os documentos emanados deste sínodo ajudam na conversão integral - pastoral, cultural, ecológica e sinodal - para promover a criação de estruturas em harmonia e cuidado com a criação. No Sínodo da Amazônia aconteceu algo inédito. Entre os documentos construídos, dois deles foram apresentados pelo Papa como oficiais. Na exortação apostólica pós-sinodal Querida Amazônia, Papa Francisco afirma:

\begin{abstract}
Aqui, não vou desenvolver todas as questões amplamente tratadas no Documento conclusivo; não pretendo substitui-lo nem repeti-lo. (...). Ao mesmo tempo, quero apresentar de maneira oficial o citado Documento, que nos oferece as conclusões do Sínodo e no qual colaboraram muitas pessoas que conhecem melhor do que eu e do que a Cúria Romana a problemática da Amazónia, porque vivem lá, por ela sofrem e a amam apaixonadamente. Nesta Exortação, preferi não citar o Documento, convidando a lê-lo integralmente. ${ }^{48}$
\end{abstract}

Foi uma forma concreta de acolher a riqueza do Documento Final do sínodo, já que era fruto de um longo, belo e sinuoso processo. No entanto Francisco, ofereceu outra via de leitura da realidade, que são os sonhos. Um modo próprio dos profetas descritos no Antigo Testamento. Não se trata do sonho como algo utópico, mas como possibilidade concreta de chegada. No primeiro sonho, o social, vislumbra-se uma Amazônia - que é símbolo de toda terra - "que integre e promova todos os seus habitantes, para poderem consolidar o 'bem viver'". ${ }^{49}$ No entanto este sonho, não projeta apenas um futuro ideal, mas fundamenta-se na realidade concreta e comporta também indignações "como se indignou Moisés, como Se indignava Jesus, como Se indigna Deus perante a injustiça. Não é salutar

\footnotetext{
${ }^{48}$ QA 2-3.

${ }^{49} \mathrm{QA} 8$.
} 
habituarmo-nos ao mal; faz-nos mal permitir que nos anestesiem a consciência social". ${ }^{50}$

Do sonho social, nasce o sonho cultural, que parte da valorização de outras culturas. Olhando para os povos indígenas, assim como poderia ser com outros povos, o Papa Francisco afirma que "temos que evitar de os considerar como 'selvagens não-civilizados'; simplesmente criaram culturas diferentes e outras formas de civilização, que antigamente registraram um nível notável de desenvolvimento". ${ }^{51}$ Os povos sobreviventes da Amazônia passaram e passam por duras investidas dos colonizadores, que espalharam miséria, destruição e morte. Esses povos "têm sua própria identidade cultural e uma riqueza única em um universo multicultural, em virtude da estreita relação que os habitantes estabeleceram com o meio circundante, em uma simbiose (...) difícil de entender com esquemas mentais alheios". ${ }^{52}$ Neste sonho se encaixa a necessidade de assumir, em qualquer projeto para a Amazônia "a perspectiva dos direitos dos povos e das culturas, (...) requer constantemente o protagonismo dos atores sociais locais a partir da sua própria cultura". ${ }^{53}$

O sonho ecológico está interligado aos sonhos anteriores. "O senhor, que primeiro cuida de nós, ensina-nos a cuidar dos nossos irmãos e irmãs e do ambiente que Ele nos dá como presente a cada dia. Essa é a primeira ecologia que precisamos". ${ }^{54}$ Nessa realidade amazônica, identifica-se que a "floresta não é um recurso para explorar, é um ser ou vários seres com os quais se relacionar". ${ }^{55}$ Ainda neste sonho, se vê a denúncia ou o grito dos povos indígenas que se reconhecem como água, ar, terra e vida do meio ambiente: "pedimos que cessem os maus-tratos e o extermínio da 'Mãe Terra'. A terra tem sangue e está sangrando, as multinacionais cortaram as veias da nossa "Mãe Terra". ${ }^{56}$ Além dos demais elementos elencados pelo Papa, gostaríamos de ressaltar ainda que este sonho não é voltado para uma ideia simplória de retorno ao jardim inicial. Mas é muito realista, sabendo que o cuidado com a Amazônia requer o conjugar "a sabedoria ancestral com os conhecimentos técnicos contemporâneos, procurando sempre intervir no território de forma

\footnotetext{
${ }^{50}$ QA 15.

${ }^{51}$ QA 29.

${ }^{52}$ QA 31.

${ }^{53}$ QA 40.

${ }^{54}$ QA 41.

${ }^{55} \mathrm{QA} 42$.

${ }^{56} \mathrm{QA} 43$.
} 
sustentável, preservando ao mesmo tempo o estilo de vida e os sistemas de valores dos habitantes". 57

O quarto sonho é o eclesial e vem da ideia de que o cristão não deve renunciar "à proposta de fé que recebe do Evangelho". ${ }^{58}$ É necessário saber o lugar que cada um ocupa no grande cenário mundial. Respeitar todos os especialistas e contar com a colaboração de todas as pessoas de boa vontade. O cristão deve estar preparado, na sua autêntica fé, para não se envergonhar de Jesus Cristo e para levar sua mensagem libertadora a todos os povos. Se pensamos nos povos indígenas, eles também têm o direito ao querigma. "É o anúncio de um Deus que ama infinitamente cada ser humano, que manifestou plenamente este amor em Cristo crucificado por nós e ressuscitado na nossa vida" ${ }^{59}$ Papa Francisco alerta para a urgência e a necessidade desse anúncio a fim de não se transformar as estruturas eclesiais em ONGs, sem desmerecer a sua importância. Mas toda ação eclesial deve passar pela inculturação social e espiritual para defender os direitos humanos e alimentar os anseios de uma dimensão transcendente com uma espiritualidade realmente cristã. Neste sentido, deve-se recordar que para viver a santidade, "não se deve copiar os modelos de outros lugares", mas "santidade feita de encontro e dedicação, de contemplação e serviço, de solidão acolhedora e vida comum, de jubilosa sobriedade e luta pela justiça". ${ }^{0}$

Em síntese, este documento é fruto do Sínodo dos Bispos para a Amazônia e constitui um percurso de escuta muito interessante para os tempos pandêmicos. Ele percorreu diversos povos e nações, dando a todos a possibilidade de ter voz e hoje é um exemplo a ser estudado, assimilado e acolhido para o fomento da vida integral. Também o Documento Final do Sínodo traz elementos essenciais que nos ajudam a entender a preocupação com a casa comum e assumirmos a nossa vocação de cuidadores do jardim da criação (Gn 2,15). O ser humano precisa retomar a consciência do cuidado com os seres criados por Deus, de modo que a harmonia da criação não desencadeie nessas pandemias avassaladoras.

\footnotetext{
${ }^{57}$ QA 51.

${ }^{58}$ QA 62.

${ }^{59}$ QA 64.

${ }^{60}$ QA 77.
} 


\section{Mensagem Urbi et orbi durante o Momento extraordinário de oração em tempo de pandemia}

No dia 27 de março de 2020, o Papa Francisco surpreendeu o mundo com a bênção "Urbi et orbi" . ${ }^{61}$ Uma oração comovente de frente para a Praça São Pedro vazia. Aquele ambiente que costuma estar repleto de pessoas de todo canto do planeta, com suas expressões de cantos e orações, de gritos e risadas, desta vez, estava em um silêncio gritante. Se ouvia apenas o barulho da chuva, que dava ao ambiente um aspecto ainda mais tenebroso. No entanto, toda a atmosfera orante, todos os elementos naturais e litúrgicos falavam e anunciavam uma mística em harmonia com o momento vivido no Planeta Terra. A começar com os passos lentos do Sumo Pontífice, sozinho, subindo as escadas da Basílica São Pedro, na chuva. Imagem tocante, que já anunciava a verdadeira situação da Igreja naquele momento.

Esta benção surpreendeu, não por ser inédita, mas pelo momento vivido, pela mística que emanava. As palavras do Papa Francisco pareciam ler bem a realidade, mas traziam um alento de esperança às pessoas amedrontadas. Ao ser questionado, em outro momento, o que sentia ao caminhar em silêncio até o adro da Basílica, ele respondeu: "caminhava assim, sozinho, pensando na solidão de tantas pessoas. Um pensamento inclusivo, um pensamento com a cabeça e com o coração, juntos. Sentia tudo isso e caminhava". ${ }^{62}$ São esses elementos de inclusão que fez com que as pessoas se sentissem contempladas com a benção Urbi et orbi. Após a leitura do Evangelho Marcos 4,35-41, o Santo Padre iniciou com uma descrição da realidade atual:

Há semanas que parece que caiu a noite. Densas trevas cobriram nossas praças, ruas e cidades; apoderaram-se das nossas vidas, enchendo tudo de um silêncio ensurdecedor e um vazio desolador, que paralisa tudo à sua passagem: pressente-se no ar, nota-se nos gestos, dizem-no os olhares. Revemo-nos temerosos e perdidos. ${ }^{63}$

O discurso falado, mas também o discurso litúrgico parecem ser uma verdadeira continuidade e comunhão com o Concílio Vaticano II, ou seja,

\footnotetext{
${ }^{61}$ FRANCISCO, PP., Mensagem Urbi et orbi durante o Momento Extraordinário de oração em tempo de epidemia, Adro da Basílica de São Pedro, 27 mar. 2020.

${ }^{62}$ FRANCISCO, PP., Por que sois tão medrosos?, p. 55.

${ }^{63}$ FRANCISCO, PP., Por que sois tão medrosos?, p. 25.
} 
menos sacristia e mais fundamentos antropológicos. É em uma espécie de antropologia teológica em que o "projeto homem" homem". Não é um movimento que coloca o ser humano no lugar de Deus, mas um movimento que procura entendê-lo à luz da fé. Para isso, Karl Rahner afirma que "não devemos considerar o problema do homem nem a reposta a este problema como área diferente, material e localmente, dos outros domínios de expressão teológica" ${ }^{65}$ ao mesmo tempo, deve-se considerar que a "teologia dogmática deve tornar-se, hoje, uma antropologia teológica". ${ }^{66}$ É o que Karl Rahner chama de Antropologia Transcendental. Nesta mesma linha, Papa Francisco não titubeia ao relacionar o momento presente com a tempestade vivida pelos discípulos. O medo, categoria bem humana, é presente em meio à tempestade. Os questionamentos também são características humanas que perpassam a estrutura de nosso corpo e de nossa mente. $\mathrm{O}$ questionamento dos discípulos a Jesus, se parece com os questionamentos atuais: "Mestre, não te importa que pereçamos?" (Mc 4,38). O Papa Francisco dirá que "entre nós, em nossas famílias, uma das coisas que mais dói é ouvirmos dizer: você não se importa comigo. É uma frase que fere e desencadeia turbulência no coração. Terá abalado também Jesus, pois não há ninguém que se importa mais conosco do que Ele". ${ }^{67}$ Ao comparar a tempestade com o momento presente, Papa Francisco, dirá que a tempestade "desmascara nossa vulnerabilidade e deixa a descoberto as falsas e supérfluas seguranças com que construímos nossos programas, nossos projetos, nossos hábitos e prioridades". ${ }^{68}$ Foi assim que, diante do Crucifixo de São Marcelo, de Roma, a Teologia da Cruz mais uma vez se fez presente, e evidenciou-se ali que da cruz:

O Senhor nos desafia a encontrar a vida que nos espera, a olhar para aqueles que nos interpelam, a reforçar, reconhecer e incentivar a graça que mora em nós. Abraçar a cruz significa encontrar a coragem de abraçar todas as contrariedades da hora atual, abandonando, por um momento, nossa ânsia de onipotência e posse, para dar espaço à criatividade que só o Espírito é capaz de suscitar. ${ }^{69}$

\footnotetext{
${ }^{64}$ MONDIN, B., L'uomo secondo il disegno di Dio, p. 12.

${ }^{65}$ RAHNER, K., Teologia e antropologia, p. 13.

${ }^{66}$ RAHNER, K., Teologia e antropologia, p. 13.

${ }^{67}$ FRANCISCO, PP., Por que sois tão medrosos?, p. 30.

${ }^{68}$ FRANCISCO, PP., Por que sois tão medrosos?, p. 30.

${ }^{69}$ FRANCISCO, PP., Por que sois tão medrosos?, p. 47.
} 
A realidade "cruz-ressurreição", não faz parte apenas de um jogo de palavras, mas faz parte de uma teologia que não nega a cruz para anunciar a ressurreição. Que entende o valor do sofrimento, não de modo narcisista, mas realista. Que sente emanar da cruz a força e a identificação divina, com as cruzes dos sofredores. Num tempo em que somos chamados a "fincar os pés" na casa comum, a caminhar para evitar um mal maior, o Papa Francisco também nos dá uma lição teológica a partir dos pés feridos de Jesus.

Beijar os pés do Crucificado sempre dá esperança. Ele sabe o que significa caminhar, e sabe que é a quarentena, porque foram-lhe colocados dois pregos ali para mantê-lo firme. Os pés de Jesus são uma bússola na vida das pessoas, quando caminham e quando estão paradas. Os pés do Senhor me tocam muito. ${ }^{70}$

Em suma, mais do que uma lição de Teologia, esta benção alimentou e continua alimentando o coração humano ferido pela tempestade da pandemia. O que seria de nós sem esta bênção? Sem as bênçãos de Deus?

\section{Conclusão}

Como alimentar a esperança diante da demência humana em uma pandemia? Diante da situação catastrófica, provocada pelo coronavírus e exacerbada pelas atitudes humanas, que provocam milhares de mortes, a perplexidade e a indignação nos levam à indagação pelo que é o ser humano. Como pode, em meio à pandemia, líderes políticos provocarem aglomerações, espalhar fake news, orientar as pessoas a usarem remédios sem eficácia comprovada, incentivar a saída de casa para trabalhar e se divertir? Como não sofrermos juntos? Como dormir tranquilos quando uns estão agonizando sem socorro? A consciência teológica nos faz entender que se um ser humano está doente é a humanidade toda que está adoecida. É necessário e urgente manter a lucidez e a fraternidade a fim de que possamos juntos buscar saídas para esta situação dramática. Fomentar mais e mais ponderações reflexivas e analíticas, como tentamos fazer neste artigo a fim de que alguma luz possa ajudar. No entanto, em tais circunstâncias, pode-se admitir que o ser humano se mostra como "sapiens sapiens e simultaneamente demens demens, ou

${ }^{70}$ FRANCISCO, PP., Por que sois tão medrosos?, p. 61. 
hoje, possivelmente, triplamente demens" ${ }^{71}$ Isso porque, felizmente, em contraposição às aberrações criminosas por parte de alguns líderes políticos, bem como de alguns religiosos e seus seguidores, surgem grandes luzes por parte de mulheres e homens que semeiam esperança. Mediante inúmeras outras boas ações que nem sempre ganham visibilidade e também pelo uso científico correto dos recursos produzidos pela mãe terra, são capazes de nos possibilitar singrar o curso da vida em busca do sonho de uma fraternidade universal.

A reflexão teológica por vocação que lhe é inerente, mesmo diante de uma catástrofe, como a atual, evidencia que o ser humano traz em si o poder da esperança, é portador do mistério e do amor. Essa esperança pode ser vista no sentido de projetar a vida para o pós-tragédia. No fundo, é a visão da vida como caminho para um fim glorioso, não no sentido de término, mas no sentido de algo além, de continuar na corresponsabilidade de reconstrução do Reino de Deus. E o fim é fonte de motivação que move o ser, já que "quando se tem um propósito claro e atraente, a vida se torna intensa e vibrante". ${ }^{72}$ Nas pegadas de Santo Tomás de Aquino é possível afirmar que "a causa final é a causa primacial, o primum movens de tudo"..$^{73}$ Nesse modo de entender, "é a causa causarum". ${ }^{74}$ Essa causa coloca em movimento todas as demais causas, determinando o agente que se move a partir de uma intenção ou de um propósito e do ponto de vista teológico, é o Deus da vida quem nos move na busca inconstante do bem.

Em suma, na dramática situação atual em que se observa que "uma emergência como a Covid-19 derrota-se antes de tudo com anticorpos da solidariedade" ${ }^{75}$ porém, desde sempre o ser humano, enquanto exposto aos acontecimentos, é exposto à graça da esperança cristã. A nível existencial, a esperança se coloca na área do desejo da felicidade, da realização de si, em vista do cumprimento das próprias aspirações. A nível de tempo, a esperança se expande enquanto espaço necessário a realizar, ou seja, existe um projetar-se ao futuro, para ver já, no presente, a sua realização. E, desse modo, apesar dos sinais de morte do presente, a reflexão teológica nos projeta para uma vida pós pandemia na esperança de que tempos melhores possam

\footnotetext{
${ }^{71}$ BOFF, L., A Terra na palma da mão, p. 78.

${ }^{72}$ BOFF, C., O livro do sentido, p. 31.

${ }^{73}$ ST I-II, q. 1, a. 6, c.

${ }^{74}$ ST I, q. 5, a. 2, ad 1.

${ }^{75}$ FRANCISCO, PP., Vida após pandemia, p. 50.
} 
ser despontados sempre. Apesar da certeza das adversidades já impostas, mas que não terão a última palavra, graças à certeza da ressurreição, e renovação da vida. Concluímos, então, com as palavras do Papa: "É verdade que uma tragédia global como a pandemia do Covid-19 despertou, por algum tempo, a consciência de sermos uma comunidade mundial que viaja no mesmo barco, onde o mal de um prejudica a todos. Recordamo-nos de que ninguém se salva sozinho, que só é possível salvar-nos juntos". ${ }^{76}$

\section{Referências bibliográficas}

AGÊNCIA ECCLESIA. Vaticano: Papa condena violência gerada pelo comsumismo e pede fim de Economia ao serviço da guerra. Agência Ecclesia, Lisboa, 01 dez. 2019. Disponível em: <https://agencia.ecclesia.pt/portal/ vaticano-papa-denuncia-violencia-gerada-pelo-consumismo-e-pede-fim-deeconomia-ao-servico-da-guerra/>. Acesso em: 05 jun. 2021.

ARENDT, H. Eichmann em Jerusalém: um relato sobre a banalidade do mal. São Paulo: Companhia das Letras, 1999.

ARENDT, H. Origens do totalitarismo. São Paulo: Companhia das Letras, 2012.

BÍBLIA de Jerusalém. Nova ed. rev. e ampl. 2. impr. São Paulo: Paulus, 2002.

BOFF, C. Conselhos a um jovem teólogo. Perspectiva teológica, v. 31. n. 83, p. 77-96, 1999.

BOFF, C. O livro do sentido: qual é, afinal, o sentido da vida? (parte teóricoconstrutiva). São Paulo: Paulus, 2018. v. 2.

BOFF, L. A Terra na palma da mão. Uma nova visão do planeta e da humanidade. Petrópolis: Vozes, 2016.

BOFF, L. A encíclica do Papa Francisco não é verde, é integral. In: MURAD, A.; TAVARES, S. S. Cuidar da casa comum: chaves de leitura teológicas e pastorais da Laudato Si'. São Paulo: Paulinas, 2016. p. 15-23.

CNBB. Arquidioceses do Brasil oferecem espaços da Igreja como hospitais de campanha. Disponível em: $<$ https://www.cnbb.org.br/arquidioceses-dobrasil-oferecem-espacos-da-igreja-como-hospitais-de-campanha/>. Acesso em: 25 mar. 2021.

${ }^{76}$ FT 32. 
FRANCISCO, PP. As bem-aventuranças e a cura do mundo. $1^{\text {a }}$ ed. São Paulo: Paulus, 2021.

FRANCISCO, PP. Carta Encíclica Fratelli Tutti: sobre a fraternidade e amizade social. São Paulo: Paulus, 2020.

FRANCISCO, PP. Carta Encíclica Laudato si': sobre o cuidado da casa comum. São Paulo: Loyola / Paulus, 2015.

FRANCISCO, PP. Catequese por ocasião do $5^{\circ}$ Dia Mundial da Terra. Audiência geral, 22 abr. 2020. São Paulo: Paulus, 2020.

FRANCISCO, PP. Exortação Apostólica Evangelii Gaudium. AAS, n. 105, p. 1020-1137, 2013.

FRANCISCO, PP. Exortação Apostólica Querida Amazônia. Brasília: Edições CNBB, 2020.

FRANCISCO, PP. Mensagem Urbi et orbi durante o Momento Extraordinário de oração em tempo de epidemia, Adro da Basílica de São Pedro, 27 mar. 2020. Disponível em: <http://www.vatican.va/content/ francesco/pt/messages/urbi/documents/papa-francesco_20200327_urbi-etorbi-epidemia.html>. Acesso em: 27 mar. 2021.

FRANCISCO, PP. Por que sois tão medrosos? Ainda não tendes fé? Statio Orbis. Brasília: CNBB; São Paulo: Paulinas / Paulus, 2021.

FRANCISCO, PP. Vida após pandemia. Città del Vaticano: Libreria Editrice Vaticana, 2020.

MENDONÇA, J. T. Livra-nos deste vírus e de todos os outros. Disponível em: <https://www.capeladorato.org/2020/04/04/que-sentido-tem-tudo-isto/>. Acesso em: 25 mar. 2021.

MENDONÇA, S. As perversidades de Bolsonaro. Folha de São Paulo, São Paulo, 26 mar. 2021. Disponível em: <https://www1.folha.uol. com.br/opiniao/2021/03/as-perversidades-de-bolsonaro.shtml?utm source $=$ whatsapp\&utm_medium $=$ social\&utm_campaign $=$ compwa $>$. Acesso em: 27 mar. 2021.

MONDIN, B. L'uomo secondo il disegno di Dio. Trattato di antropologia teologica. Bologna: ESD-Edizioni Studio Domenicano, 2011.

PORTAL HOSPITAIS BRASIL. Vacinação obrigatória tem respaldo na lei e governo pode exigir imunização contra a Covid-19. Portal Hospitais Brasil, 
São Paulo, 04 nov. 2020. Disponível em: <https://portalhospitaisbrasil. com.br/vacinacao-obrigatoria-tem-respaldo-na-lei-e-governo-pode-exigirimunizacao-contra-covid-19/>. Acesso em: 03 jun. 2021.

QUEIRUGA, A. T. Recuperar a Criação. Por uma religião humanizadora. São Paulo: Paulus, 1999.

RAHNER, K. Teologia e antropologia. São Paulo: Paulinas, 1969.

SÀNCHEZ, J. J. Absoluto. In: PIKAZA, X.; SILANES, N. Dicionário teológico: o Deus Cristão. São Paulo: Paulus, 1988. p. 1-3.

TOMÁS de Aquino. Suma Teológica. v. I, parte I. São Paulo: Edições Loyola, 2001.

VOA PORTUGUÊS. Papa Francisco diz que a decisão de tomar vacina COVID é uma questão ética. Voa Português, 10 jan. 2021. Disponível em: $<$ https:// www.voaportugues.com/a/papa-francisco-diz-que-decisão-de-receber-avacina-covid-é-uma-questão-de-ética/5731862.html>. Acesso em: 05 jun. 2021.

José Aguiar Nobre

Doutor em Teologia pela Pontifícia Universidade Católica do Rio de Janeiro Docente do Departamento de Teologia da Pontifícia Universidade

Católica de São Paulo

São Paulo / SP - Brasil

E-mail: nobre.jose@gmail.com

Elizeu da Conceição

Doutor em Teologia pela Università Pontificia Salesiana

São Paulo / SP - Brasil

E-mail: uezile2008@gmail.com

Recebido em: 30/03/21

Aprovado em: 14/06/21 